\title{
ATTITUDE TOWARDS ANATOMY AS A PROSPECTIVE CAREER AMONG UNDERGRADUATE MEDICAL STUDENTS
}

Rubi Saikia', Natasha Gohain², Santanu Kr. Sarma³

\section{HOW TO CITE THIS ARTICLE:}

Rubi Saikia, Natasha Gohain, Santanu Kr. Sarma. "Attitude towards Anatomy as a Prospective Career among Undergraduate Medical Students". Journal of Evolution of Medical and Dental Sciences 2015; Vol. 4, Issue 41, May 21; Page: 7122-7126, DOI: 10.14260/jemds/2015/1036

ABSTRACT: The proportion of medical students opting for anatomy as a prospective career is seen to be very less as compared to those choosing a clinical subject. The study was undertaken to find out the attitudes of undergraduate medical students towards anatomy in comparison to other paraclinical and clinical subjects. A set of questionnaire was given to three hundred undergraduate students and their responses were compiled. Only 9(3\%) students opted for anatomy as a career choice. Majority, 239(79.6\%) of the students preferred to go for a clinical subject in future. Anatomy also rated poorly in terms of financial benefit \& social status. The present study shows that the students possess a negative attitude towards anatomy which needs to be changed urgently.

KEYWORDS: Attitude, anatomy, pre \& paraclinical, prospective career.

INTRODUCTION: Anatomy is one of the basic preclinical subjects offered during first year of MBBS course. A full flagged anatomy department is a must in every medical college, where students dissect, see and learn about the human body under guidance of trained teachers. It has been observed that very few medical students opt for anatomy as a career of choice. In fact, only the graduates with lower rank in postgraduate entrance exam choose anatomy as a last resort. This is of immense concern because the number of qualified teachers in anatomy as well as in other preclinical subjects is gradually decreasing.(1) Often, the postgraduate seats in anatomy either go vacant or partially filled. In the light of low recruitment in this subject, this study was carried out among the undergraduate students of Assam Medical College, Dibrugarh, Assam, to know their attitude towards anatomy as a career in future.

MATERIALS AND METHODS: The present study was carried out in Assam Medical College, Dibrugarh, Assam. A total of three hundred undergraduate students were selected randomly. This included students from first year to the final year. With the help of persons belonging to departments not included in the present study, they were informed about the study and their verbal consent was taken. In this way, they were kept in dark regarding which department was involved in conducting the study so that they feel free to give their opinion. The students were also assured that the information so collected would be used only for study purpose. Due permission from the concerned authority was taken before commencement of the study. Each student was given a set of questionnaires and were asked to provide a response. The findings were analysed later on.

RESULT AND OBSERVATIONS: All the three hundred students returned the completed questionnaires. Among the participants, 146(48.6\%) were females and 154(51.3\%) were males. They were in the age group of 18 to 24 years. Here's what they said. 


\section{ORIGINAL ARTICLE}

\begin{tabular}{|c|c|c|c|c|c|}
\hline Pathology & Medicine & Surgery & Anatomy & Obstetrics \& Gynaecology & Ophthalmology \\
\hline 20 & 85 & 81 & 9 & 80 & 25 \\
\hline \multicolumn{7}{|c|}{ Table 1: Showing the Subject Preference as a Career } \\
\hline
\end{tabular}

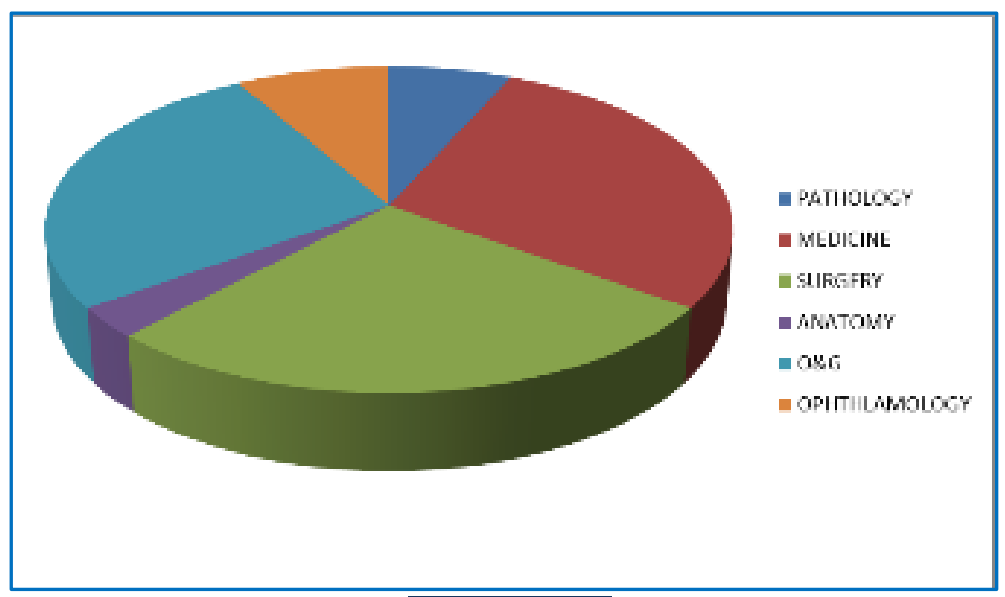

Chart 1

\begin{tabular}{|c|c|c|c|c|c|}
\hline $\begin{array}{c}\text { Interesting } \\
\text { subject }\end{array}$ & $\begin{array}{c}\text { Financial } \\
\text { benefit }\end{array}$ & $\begin{array}{c}\text { Prestige among } \\
\text { the public }\end{array}$ & $\begin{array}{c}\text { Holds a bright } \\
\text { future }\end{array}$ & $\begin{array}{c}\text { Patient } \\
\text { care }\end{array}$ & $\begin{array}{c}\text { Rapidly } \\
\text { advancing }\end{array}$ \\
\hline 20 & 146 & 55 & 34 & 11 & 34 \\
\hline \multicolumn{7}{r}{ Table 2: Showing the Reason Behind the Choosen Subject }
\end{tabular}

\begin{tabular}{|c|c|c|c|}
\hline A clinical subject & A para-clinical subject & A pre-clinical subject & Any subject that I get \\
\hline 239 & 11 & 10 & 40 \\
\hline
\end{tabular}

Table 3: Showing students preference of a career after graduation

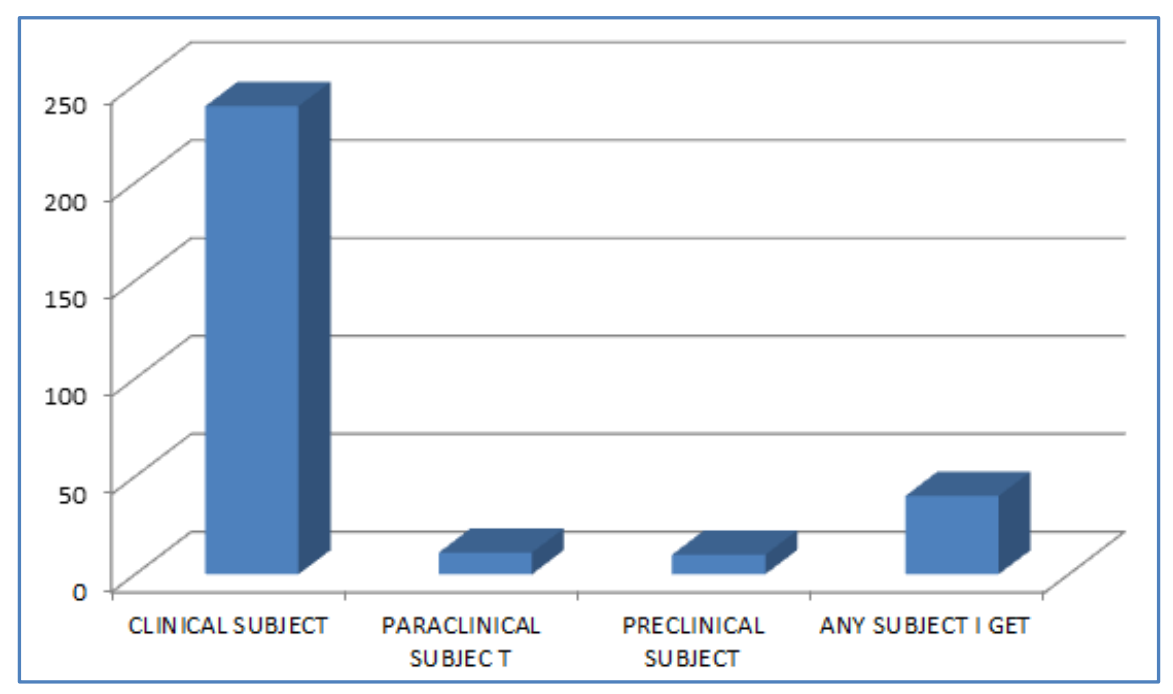

Chart 2 


\begin{tabular}{|c|c|c|c|}
\begin{tabular}{|c|} 
They want me to \\
choose a clinical \\
subject
\end{tabular} & $\begin{array}{c}\text { They want me to take up a } \\
\text { para-clinical subject }\end{array}$ & $\begin{array}{c}\text { They want me to take } \\
\text { up a pre-clinical } \\
\text { subject }\end{array}$ & $\begin{array}{c}\text { The choice is } \\
\text { totally mine }\end{array}$ \\
\hline 232 & 14 & 4 & 50 \\
\hline \multicolumn{2}{r}{ Table 4: Showing Families' Influence \& Pressure in Choosing a Career } \\
\hline
\end{tabular}

\begin{tabular}{|c|c|c|c|}
\hline Subjects & Very much & Moderate & Very little \\
\hline Pathology & 53 & 148 & 99 \\
\hline Medicine & 132 & 147 & 21 \\
\hline Surgery & 161 & 97 & 42 \\
\hline Anatomy & 21 & 108 & 171 \\
\hline O \& G & 154 & 117 & 29 \\
\hline Ophthalmology & 91 & 86 & 123 \\
\hline
\end{tabular}

Table 5: Showing Students Likeness for Different Subjects

In the present study, it was found that majority of the students $(79.6 \%)$ preferred a clinical subject over para-clinical (3.6\%) and pre-clinical (3.3\%) subjects as a career in future (Table 3 ). Infact, anatomy ranked very poorly (3\%) as compared to other subjects (Table 1). Students also believe that clinical subjects are financially rewarding, more prestigious and satisfactory. When asked if they will try to take up the subject their family wants for postgraduation, $232(77.3 \%)$ students agreed. When asked to estimate the degree to which they like the subjects, anatomy was liked very much by only 21 students (Table 5).

DISCUSSION: Though anatomy is one of the basic subjects in medical science, it can be understood from the above observations that the students carry a negative impression of anatomy as compared to other paraclinical and clinical specialities. The non-clinical teaching specialities are opted for by very few students. ${ }^{(2)}$ The fresh students don't even mention anatomy as a choice of postgraduation. ${ }^{3,4)}$ The findings of the present study too confirms this fact. This attitude of the students towards anatomy is probably due to the discomfort and uneasiness they experienced during their first year of MBBS course. ${ }^{(5,6,7,8,9)}$ In this study, only $9(3 \%)$ students opted for anatomy as a career while $10(3.3 \%)$ said that they might take up a preclinical subject but not anatomy.(1) The possible reason for declining interest in anatomy could be multiple starting with the experience of first year in the dissection hall. This is indeed a matter of concern as it predicts acute shortage of teaching faculty in years to come.(10)

Majority of the students, $146(48.6 \%)$ opted for a clinical subject as a career because of its financial benefit and prestige in the society. ${ }^{(11,12,13)}$ It is true that persons associated with professions involving preclinical subjects experience limited financial returns.(14) Moreover, research opportunities in the field of anatomy is very limited in our country which could be yet another reason for not choosing it as a career. If facilities like cytogenetic laboratory is made available in the anatomy department of every medical college, students might start giving it a second thought about anatomy as a prospective career. Efforts should be made to make the students realize that anatomy is a very 
interesting subject and has made tremendous advances over the past few decades. With better understanding of cross- sectional anatomy, neuro-anatomy and embryology, we, the anatomists can help the students overcome the difficulties in becoming a better doctor. This gives as much satisfaction as treating a patient in pain.

CONCLUSION: There is a shortage of teachers in preclinical subjects at a global label. The present study indicates that the scarcity of anatomists in India would prevail for many more years to come if immediate measures are not taken to improve the situation. No modern teaching techniques can replace a trained anatomist. To make the subject more interesting among the medical students integrated teaching schedule should be adopted, better research opportunities should be provided, periodical training courses to the teachers should be offered and if possible, some incentives for attending conferences should be granted to the preclinical teachers of all medical colleges across India.

\section{REFERENCES:}

1. Schockley DG. In quest of profound courtesy: chaplin enters the anatomy lab. The Christian century 1986; Sept 24: 808-10.

2. Schumacher CT. Personal characteristics of students choosing different type of medical career. Journal of medical education 1964; 39: 278-288.

3. Soufi HE. Attitude of medical students towards psychiatry. Medical Education 1992: 26: 38-4.

4. Tolani B. Continuing medical education and career choice among graduates of problem based and traditional curricula. Medical education 1991; 25(5): 414-20.

5. Dr G. Agnihotri \& M. G. Sagoo. Reactions of first year Indian Medical students to the dissection hall experience. NJIRM 2010, Vol 1(4) Oct- Dec.

6. M. H. Bob et al. First year medical students attitude towards anatomical corpse dissection \& its relationship with their personality. RJME, 2015; 56(1): 321-324.

7. Plaisant $O$ et al. Medical students attitude towards science \& gross anatomy \& the relationship to personality. PubMed- NCBT, J. Anat 2014 Mar; 224(3): 261-9.

8. Leboulanger N. First cadaver dissection: stress, preparation \& emotional experience. Eur Ann Otorhinolaryngol Head Neck Dis, 2011, 128(4): 175-183.

9. Tschering $\mathrm{T}$ et al. Emotional reactions of medical students to dissecting room bodies: A conceptual approach \& its evaluation. Anatomical Rec. Part B: New Anatomist 2000; 261:1113.

10. Anand MK et al. Anatomy as a subject \& career option in view of medical students in India. J. Anat. Soc. India 53(1)10-14(2004).

11. Anand BK. Manpower recruitment of medical teacher, measures for meeting the requirements. Indian Journal of Medical Education 1992; 31: 2, 50-54.

12. Anantraman V et al. MBBS students observations on pre \& paraclinical subjects. J. Anat Sci 1995; 14: 1, 31-33.

13. Galazika Sim S et al. Method of recruiting \& selecting resident for US family practice residencies. Academic Medicine 1994; 4(69): 1-4.

14. Abraham S. The dominance of research in staffing medical school, time for change? Lancet 1991; 337: 1586-8. 


\section{ORIGINAL ARTICLE}

\section{AUTHORS:}

1. Rubi Saikia

2. Natasha Gohain

3. Santanu Kr. Sarma

\section{PARTICULARS OF CONTRIBUTORS:}

1. Associate Professor, Department of Anatomy, Assam Medical College, Dibrugarh, Assam.

2. Demonstrator, Department of Anatomy, Assam Medical College, Dibrugarh, Assam.

FINANCIAL OR OTHER COMPETING INTERESTS: None
3. Demonstrator, Department of Anatomy, Tezpur Medical College, Tezpur, Assam.

\section{NAME ADDRESS EMAIL ID OF THE}

\section{CORRESPONDING AUTHOR:}

Dr. Rubi Saikia,

Associate Professor,

Department of Anatomy,

Assam Medical College,

Dibrugarh-786002, Assam.

E-mail: drrubisaikia@gmail.com

Date of Submission: 28/04/2015.

Date of Peer Review: 29/04/2015.

Date of Acceptance: 13/05/2015.

Date of Publishing: 19/05/2015. 